\title{
Association between serum visfatin and carotid atherosclerosis in diabetic and non-diabetic patients on maintenance hemodialysis
}

Samia Hassan El-Shishtawy ${ }^{1}$, Osama Mosbah ${ }^{1}$, Nevine Sherif ${ }^{1}$, Amna Metwaly $^{2}$, Amr Hanafy $^{3}$, Laila Kamel ${ }^{4}$

${ }^{1}$ Nephrology Department, Theodor Bilharz Research Institute, Giza, Egypt

${ }^{2}$ Intensive Care Department, Theodor Bilharz Research Institute, Giza, Egypt

${ }^{3}$ Cardiology Department, Aswan University, Aswan, Egypt

${ }^{4}$ Clinical Chemistry Department, Theodor Bilharz Research Institute, Giza, Egypt

\section{Type of article: Original}

\begin{abstract}
Introduction: Adipose tissue releases bioactive factors termed adipokines. Visfatin is an adipokine that plays an active role promoting vascular inflammation and atherosclerosis. The purpose of this study was to determine the association between serum visfatin levels and carotid atherosclerosis in diabetic and non-diabetic patients on maintenance hemodialysis (HD) in order to clarify the role of serum visfatinas, a risk factor for cardiovascular complications in HD patients.

Methods: Forty patients on maintenance hemodialysis were enrolled in this case-control study in 2015 . They were subdivided into two groups, i.e., a diabetic group $(\mathrm{n}=20)$ and a non-diabetic group $(\mathrm{n}=20)$. Twenty healthy subjects who were age and gender matched were included as a control group. Carotid Duplex studies were performed on all patients, and serum visfatin was determined by a competitive enzyme immunoassay.

Results: HD patients showed a highly significant increase in serum visfatin, urea, creatinine, $\mathrm{Ca} \times \mathrm{Ph}, \mathrm{K}$, fasting glucose, triglycerides, LDL levels, and a significant decrease in eGFR, Na, HDL, and Hb compared to the control group. Also, serum visfatin levels showed a highly significant increase in the diabetic HD group compared to both the non-diabetic HD and control groups. Serum visfatin showed a highly significant increase in non-diabetic HD patients compared to the control group. Carotid intima-media thickness (IMT) showed a highly significant increase in HD group compared to the control group. Serum visfatin correlated positively with serum urea, creatinine, glucose, and IMT, but it was negatively correlated with eGFR, Na, and HDL

Conclusion: We concluded that serum visfatin is increased in HD patients with and without diabetes. Moreover, its association with IMT may be involved in the pathogenesis of atherosclerosis in CRF patients.

Keywords: chronic kidney disease, visfatin, carotid intima-media thickness, hemodialysis
\end{abstract}

\section{Introduction}

Chronic kidney disease (CKD) is now considered one of the strongest risk factors for all causes of mortality and cardiovascular events. Furthermore, endothelial dysfunction, smooth muscle cell proliferation, and atherosclerosis are highly common in CKD and may be implicated in the pathogenesis of cardiovascular disease (CVD) (1). Because traditional risk factors alone cannot explain the high prevalence of CVD in CKD patients, inflammation, oxidative stress, and insulin resistance are being studied increasingly as important, non-traditional risk factors (2). Adipose tissue is now known to be a hormonally-active organ that releases a large number of bioactive proteins and adipokines that regulate body weight, energy homeostasis, insulin resistance, blood lipid levels, endothelial health, coagulation, fibrinolysis, and inflammation $(3,4)$. Patients with CKD have markedly elevated serum levels of Adipokine, which probably is due to decreased renal excretion $(5,6)$. Visfatin is an adipokine that was identified in 2004, and its name suggests that it is produced predominantly and secreted in visceral fat (7). Its genes encode 491 amino acids, and it has a molecular weight of $52 \mathrm{kDa}$. It is identical to pre-B cell colony-enhancing factor, which

\section{Corresponding author:}

Nevine Sherif, Nephrology Department, Theodor Bilharz Research Institute, Giza, Egypt.

E-mail: nevinesherif@yahoo.com

Received: December 08, 2015, Accepted: January 28, 2016, Published: February 2016

iThenticate screening: January 28, 2016, English editing: February 05, 2016, Quality control: February 07, 2016

(C) 2016 The Authors. This is an open access article under the terms of the Creative Commons Attribution-NonCommercialNoDerivs License, which permits use and distribution in any medium, provided the original work is properly cited, the use is non-commercial and no modifications or adaptations are made. 
was described in 1994 as a cytokine that is produced by lymphocytes that acts on the maturation of lymphocytes and serves as a regulator of inflammatory responses. Visfatin also was recognized recently as the formerly described nicotinamide phosphoribosyltransferase (NAmPRTase), which is the limiting enzyme in nicotinamide adenine dinucleotide biosynthesis that is involved in the production of reactive oxygen species $(8,9)$. Visfatin has been the subject of extensive research due to its pleiotropic action. Interestingly, it also acts as an inflammatory cytokine, with its levels becoming elevated in several acute and chronic inflammatory diseases, such as sepsis, acute lung injury, rheumatoid arthritis, and inflammatory bowel disease (10). Also, Axelsson et al. (11) found that visfatin is associated with the biomarker of endothelial damage in CKD, i.e., soluble vascular adhesion molecule 1. An association has been observed between proteinuria, which is an important predictor of endothelial dysfunction (ED) in early diabetic nephropathy, and visfatin level (12). In 2007, Axelsson et al. (11) reported an increased serum level of visfatin in chronic kidney disease (CKD). Subsequently, several other studies reported a similar relationship (13, 14). Serum visfatin concentration was significantly higher in uremic patients on hemodialysis compared with the control; serum visfatin is upregulated in these patients. However, further investigations of the relationship between serum visfatin and the various pathophysiological aspects of renal disease are warranted (15). Elevated visfatin related to markers of inflammation might represent a novel link between inflammation and adipocytokines in dialyzed patients. Time on dialyses and dialysis adequacy may influence visfatin in dialyzed patients due to the decreased clearance of visfatin (16). This study was designed to assess visfatin as an adipokine in patients on maintenance hemodialysis in conjunction with carotid duplex assessment in order to clarify its role as a risk factor for CV complications in HD patients.

\section{Material and Methods}

\subsection{Research design and patients}

This case-control study was conducted in 2015 on 60 subjects divided into two groups as follows:

1) Hemodialysis group (HD) $(n=40)$ : They were patients selected from the hemodialysis unit of Theodor Bilharz Research Institute. They went through regular sessions of hemodialysis three times per week. They were dialyzed using hemophan membranes. Dialysis was done using an acetate solution for four hours in each session. HD patients were subdivided further into a) a diabetic HD group $(\mathrm{n}=20)$ and $\mathrm{b})$ a nondiabetic HD group $(\mathrm{n}=20)$.

2) Control group $(n=20)$ : They were 20 healthy individuals who were age and gender matched with the subjects.

\subsection{Exclusion criteria}

Patients with acute and chronic inflammatory diseases, including sepsis, acute lung injury, rheumatoid arthritis, and inflammatory bowel disease were excluded from the study.

\subsection{Data collection and laboratory methods}

All subjects were subjected to the following:

1) Informed written consents were obtained from all patients according to the declaration of Helsinki.

2) Full history taking.

3) Clinical examination to detect signs of CV complications and to confirm the diagnosis.

4) Carotid Duplex: A $7.5 \mathrm{MHz}$, high-resolution probe was used to conduct ultrasonographic studies on the carotid arteries. The intima-media thickness (IMT) was defined as a low-level echo gray band that does not project into the arterial lumen. This band was measured during end-diastole as the distance from walls of the distal segment of the common carotid artery, the carotid bifurcation, and the initial tract of the internal carotid artery on both sides.

5) Laboratory Investigations: $5 \mathrm{ml}$ of venous blood samples were withdrawn from the anticubital vein from all subjects after they had fasted 12-16 hours overnight fast under aseptic conditions. Routine tests were performed immediately, and aliquots were stored at $-60{ }^{\circ} \mathrm{C}$ for further estimation of serum levels of visfatin. The laboratory tests included: A) Routine laboratory investigations included fasting glucose, creatinine, urea, calcium, phosphorus, sodium, potassium, total cholesterol, triglycerides, HDL, and Hemoglobin. We calculated the estimated GFR using the modified diet renal disease (MDRD) equation as follows: eGFR $\left(\mathrm{mL} / \mathrm{min} / 1.73 \mathrm{~m}^{2}\right)=175 \times(\mathrm{sCr})^{-1.154} \times(\text { Age })^{-0.203} \times 0.742$ (if female); B) Special laboratory tests, included serum visfatin that was determined by a competitive enzyme immunoassay kit supplied by Sigma-Aldrich (St. Louis, MO, USA). According to the manufacturer, the lowest detection concentration of visfatin was $379 \mathrm{pg} / \mathrm{ml}$, intra-assay $\mathrm{CV}<10 \%$ and interassay $\mathrm{CV}<15 \%$. 


\subsection{Statistical Analysis}

Statistical analysis was performed using SPSS version 17 (SPSS, Inc., Chicago, Illinois, USA). Data were expressed as the mean \pm standard deviation $(\mathrm{SD})$ for numerical variables. $p \leqslant 0.05$ was considered to be statistically significant, and $\mathrm{p}<0.01$ was considered to be highly statistically significant.

\section{Results}

Demographic features of the studied groups are presented in Table 1. Our study revealed that serum levels of visfatin, urea, creatinine, phosphorus, $\mathrm{Ca} \times \mathrm{Ph}$, potassium, fasting glucose, triglycerides, and LDLc showed a statistically significant increase in HD patients compared to the control group. In HD patients, there was a statistically significant decrease in eGFR, $\mathrm{Na}, \mathrm{HDLc}$, and $\mathrm{Hb}$ compared to the control group (Table 2). In diabetic HD patients, serum visfatin levels showed a highly significant increase compared to both non-diabetic HD patients and the control group. Also, there was a highly significant increase in visfatin in non-diabetic patients compared to the control group. (Visfatin levels were 110.32 $\pm 46.98,68.90 \pm 11.03$, and $58.24 \pm 8.56$ in the diabetics on HD, non-diabetics on HD, and the control group, respectively, with $p<0.01$ versus the control group and $p<0.01$ versus the non-diabetics group.) Carotid intima-media thickness showed a highly significant increase in the HD patients compared to the control group. (IMTs were $1.10 \pm 0.18$ and $0.44 \pm 0.14$ in the HD and control groups, respectively, $\mathrm{p}<0.01$.) In the hemodialysis patients, serum visfatin was correlated positively with urea, creatinine, and IMT, and it was correlated negatively with eGFR, Na, and HDL (Table 3).

Table 1. Demographic features of the studied groups

\begin{tabular}{|c|c|c|c|}
\hline \multicolumn{2}{|c|}{ Variables } & HD group & Control group \\
\hline \multicolumn{2}{|c|}{ Age (years) } & $52.94 \pm 14.14$ & $43.17 \pm 10.24$ \\
\hline \multirow[t]{2}{*}{ Gender } & Male [n (\%)] & $22(55 \%)$ & $12(60 \%)$ \\
\hline & Female $[\mathrm{n}(\%)]$ & $18(45 \%)$ & $8(40 \%)$ \\
\hline \multicolumn{2}{|c|}{ Duration of dialysis (months) } & $60.60 \pm 51.28$ & - \\
\hline \multicolumn{2}{|c|}{ Body mass index $\left(\mathrm{kg} / \mathrm{m}^{2}\right)$} & $28.20 \pm 3.84$ & $26.60 \pm 3.59$ \\
\hline \multicolumn{2}{|c|}{$\begin{array}{l}\text { DM patients [n (\%)] } \\
\text { Non-DM patients [n (\%)] }\end{array}$} & $\begin{array}{l}20(50 \%) \\
20(50 \%)\end{array}$ & $\begin{array}{l}0 \% \\
20(100 \%)\end{array}$ \\
\hline \multicolumn{2}{|c|}{ Hypertension [n (\%)] } & $18(45 \%)$ & $0 \%$ \\
\hline
\end{tabular}

Table 2. Laboratory data of all studied groups

\begin{tabular}{|c|c|c|}
\hline Variables & HD group & Control group \\
\hline Urea (mg/dl) & $94.03 \pm 29.74 * *$ & $33.47 \pm 8.63$ \\
\hline Creat (mg/dl) & $9.05 \pm 2.68 * *$ & $0.78 \pm .17$ \\
\hline eGFR & $7.74 \pm 3.36^{* * *}$ & $114.18 \pm 27.38$ \\
\hline $\mathrm{Ca}(\mathrm{mg} / \mathrm{dl})$ & $9.03 \pm .94$ & $9.13 \pm .57$ \\
\hline Po4 (mg/dl) & $5.13 \pm 1.87^{* *}$ & $4.09 \pm .74$ \\
\hline $\mathrm{Ca} \times \mathrm{P}$ & $45.69 \pm 15.26^{*}$ & $37.29 \pm 6.96$ \\
\hline $\mathrm{Na}(\mathrm{mg} / \mathrm{dl})$ & $130.76 \pm 4.42^{* * *}$ & $139.25 \pm 3.67$ \\
\hline $\mathrm{K}(\mathrm{mg} / \mathrm{dl})$ & $4.70 \pm .82 \%$ & $4.32 \pm .48$ \\
\hline Glucose (mg/dl) & $144.77 \pm 61.78^{* *}$ & $104.16 \pm 23.32$ \\
\hline Cholesterol (mg/dl) & $162.40 \pm 37.35$ & $145.16 \pm 35.25$ \\
\hline $\mathrm{TG}(\mathrm{mg} / \mathrm{dl})$ & $206.84 \pm 129.40 * *$ & $118.60 \pm 23.86$ \\
\hline LDLc (mg/dl) & $97.41 \pm 32.91^{* * *}$ & $70.60 \pm 14.92$ \\
\hline HDLc (mg/dl) & $32.37 \pm 3.67$ ** & $54.95 \pm 7.06$ \\
\hline $\mathrm{Hb}(\mathrm{gm} / \mathrm{dl})$ & $10.40 \pm 1.69^{*}$ & $11.60 \pm 1.79$ \\
\hline Visfatin(ng/ml) & $91.29 \pm 40.71^{* * *}$ & $58.24 \pm 8.56$ \\
\hline
\end{tabular}

${ }^{*} \mathrm{p}<0.05, \quad{ }^{*} \mathrm{p}<0.001$ versus control group; eGFR, estimated glomerular filtration rate; HDLc, highdensitylipoprotein cholesterol; LDLc, low-density lipoprotein cholesterol 
Table 3. Correlations of serum visfatin $(\mathrm{ng} / \mathrm{ml})$ and different parameters in the HD group

\begin{tabular}{|l|l|l|}
\hline Variables & $\mathrm{r}$ & $\mathrm{p}$-value \\
\hline Urea & 0.43 & 0.008 \\
\hline Creatinin & 0.47 & 0.004 \\
\hline HDLc & -0.411 & 0.004 \\
\hline eGFR & -0.55 & 0.001 \\
\hline IMT & 0.41 & 0.002 \\
\hline
\end{tabular}

\section{Discussion}

Atherosclerotic vascular complications are the main cause of premature morbidity and mortality of patients with CKD (17). However, it is now recognized that factors peculiar to inflammation have an important role in the pathogenesis of cardiovascular disease among these patients (18). The causes of inflammation among patients with CKD are complex and multifarious (2). A recent study indicated that adipose tissue is an active endocrine organ and can secret numerous adipokines, such as leptin, adiponectin, and visfatin (19). Visfatin is an adipokine with proinflammatory properties and is considered as a new marker of inflammation via either a compensatory response or an epiphenomenon (20). This study was designed to assess visfatin as an adipokine in patients on maintenance hemodialysis in conjunction with carotid duplex assessment in order to clarify its role as a risk factor for CV complications in HD patients. In our study, we demonstrated a statistically significant difference in serum TG, LDLc, and HDLc levels in the HD group compared to the control group. Previous studies $(21,15)$ had similar results, showing that higher visfatin levels were associated with decreased GFR, increased serum triglyceride and LDL cholesterol levels, and impaired endothelial function. Therefore, one would expect an increased probability of cardiovascular events in CKD patients with elevated serum visfatin concentrations due to their increased levels of TG and their reduced level of HDL cholesterol (21). BMI did not show any statistical significant difference between the HD and control group. This result was in agreement with $\mathrm{Mu}$ et al. (21). Our study showed statistically significant increase in serum visfatin in the HD group compared to the control group $(p<0.01)$; this result was in agreement with different studies on CKD from different perspectives $(11,22,23)$. However, our results were in disagreement with the results of other researchers who found decreased serum visfatin among end-stage renal disease (ESRD) patients treated by hemodialysis. This may be attributed to the fact that their patients showed a reduction in body fat mass with increased insulin levels, since insulin is known to suppress visfatin levels (24). Due to the dramatic effect of the loss of renal function on excreting cytokines and adipokines, the systemic effect of visfatin may be greater in CKD patients than in the general population. Also, Axelsson et al. (11) found that visfatin was associated with soluble vascular adhesion molecule 1, which is a biomarker of endothelial damage (ED) in CKD. In addition, since proteinuria is an important predictor of ED in early diabetic nephropathy, an association can be observed between proteinuria and visfatin levels (14). Increased visfatin expression also has been identified in $\mathrm{CKD}$, which is now regarded as a chronic low-grade inflammatory disease (21). A statistically significant increase was found in serum visfatin level in the diabetic group compared to the non-diabetic group $(\mathrm{p}<0.01)$. In contrast to our results, one study (23) reported no statistically significant difference between the diabetic and non-diabetic groups. This was explained by the role of visfatin in the production of ROS, which strongly supports the concept that visfatin could be one of the cytokines responsible for renal damage in diabetic nephropathy (25). In HD patients, there was a positive correlation between serum visfatin and seum creatinine and blood urea levels and a significant negative correlation with estimated glomerular filtration rate (eGFR). This was in agreement with others, who stated that subjects, with even mild renal dysfunction, also had significant accumulations of visfatin, and visfatin is related inversely to eGFR. They suggested that progressive loss of renal excretion capacity may be involved in the pathogenesis of visfatin accumulation (26). We demonstrated a significant negative correlation between visfatin and (HDLc) among patients with renal impairment. This was in agreement with Mu et al. who supported, at least in part, the role of visfatin in uremia-related atherosclerosis (21). However, Lotfy et al. showed no significant correlation between serum visfatin and HDLc (15). IMT showed a statistically significant difference between HD and control group ( $<0.01$ ), suggesting that visfatin may reflect the degree of atherosclerosis in the carotid vascular bed of HD patients. Clinical studies have shown that CKD patients are more prone to suffering from atherosclerosis than normal subjects (27). Axelsson et al. showed that serum visfatin is more elevated in patients with CKD stage 5 than in those with CKD stages 3 or 4 , and further found that serum (pro-B cell colony enhancing factor) PBEF/visfatinis positively correlated with soluble vascular cell adhesion molecule 1 (VCAM-1), a marker of endothelial damage, in patients with CKD stage 5 (11). 
Recently, one study suggested that visfatin is localized to foam cell macrophages within unstable atherosclerotic lesions, which might play a role in plaque destabilization (28). Because visfatin displays potential pro-inflammatory action and has been found to be expressed in human atherosclerotic plaques, the ubiquitous adipokine may directly participate in the development of atherosclerosis in CKD patients (21). This was in agreement with others who demonstrated increased prevalence of CVD in CKD patients with detectable carotid plaques, and we explained this finding by the presence of significant trend towards more pro-atherogenic values with decreasing GFR, proposing the reason associated with the development of atherosclerosis in CKD patients (26). A cross-talk between adipose tissue and the endothelium has been discovered in recent research, and this issue is being investigated extensively. Numerous studies have suggested that visfatin has an important role as both an intracellular and extracellular regulator of vascular function $(29,30)$. Visfatin even has been described as extending the lifespan of the cells in smooth muscles by augmenting SIRT1-mediated p53 degradation (31). Also, visfatin promotes the acquisition of a mature, smooth, muscle-cell phenotype in a nicotinamide adenine dinucleotide (NAD)-dependent way, which is an important step in terminating smooth muscle cell-mediated remodeling of diseased arteries (32). Thus, visfatin may function as a survival factor in smooth muscle cells and limit aberrant vascular remodeling. Furthermore, visfatin has been shown to promote angiogenesis, and it is negatively correlated with vascular endothelial function in vivo (33).

\section{Conclusions}

After thorough analysis of our results, we concluded that visfatin is up-regulated in patients on maintenance hemodialysis with and without diabetes. Also, its association with IMT suggests that it is involved in the pathogenesis of atherosclerosis in HD patients and that it may be a marker of endothelial damage in CKD. Future research will be directed at developing therapeutic approaches targeting visfatin. Inflammation and endothelial dysfunction are a common pathological events in many diseases, including ischemic heart disease and chronic kidney disease. Thus, determining ways to block inflammatory cytokines may provide a vital approach for preventing, or at least retarding, the progression of such diseases.

\section{Acknowledgments:}

We thank the hemodialysis unit of Theodor Bilharz Research Institute for its contributions to this study.

\section{Conflict of Interest:}

There is no conflict of interest to be declared.

\section{Authors' contributions:}

All authors contributed to this project and article equally. All authors read and approved the final manuscript.

\section{References}

1) De Mutsert R, Grootendorst DC, Axelsson J, Boeschoten EW, Krediet RT, Dekker FW. Excess mortality due to interaction between protein energywasting, inflammation and cardiovascular disease in chronicdialysis patients. Nephrol Dial Transplant. 2008; 23: 2957-64. doi: 10.1093/ndt/gfn167, PMID: 18400817.

2) Pecoits-Filho R, Heimburger O, Barany P, Suliman M, Fehrman-Ekholm I, Lindholm B, et al. Associations between circulating inflammatory markers and residual renal function in CRF patients. Am J Kidney Dis. 2003; 41: 1212-8. doi: 10.1016/S0272-6386(03)00353-6, PMID: 12776273.

3) Heimburger $\mathrm{O}$, Stenvinkel $\mathrm{P}$. Adipokines in chronic kidney disease: fat tissue gives nephrologists a message. Perit Dial Int. 2005; 25: 340-2. PMID: 16022088.

4) Tedgui A, Mallat Z. Cytokines in atherosclerosis: pathogenicand regulatory pathways. Physiol Rev. 2006; 86: 515-81. doi: 10.1152/physrev.00024.2005, PMID: 16601268.

5) Axelsson J, Bergsten A, Qureshi AR, Heimburger O, Barany P, Lonnqvist F. Elevated resistin levels in chronic kidney disease areassociated with decreased glomerular filtration rate and inflammation, but not with insulin resistance. Kidney Int. 2006; 69: 596-604. doi: 10.1038/sj.ki.5000089, PMID: 16395259.

6) Chitalia N, Raja RB, Bhandara $T$, et al. Serum adiponectin and cardiovascular risk in chronic kidney disease and kidneytransplantation. J Nephrol. 2010; 23: 77-84. PMID: 20091490.

7) Fukuhara A, Matsuda M, Nishizawa M, Segawa K, Tanaka M, Kishimoto K, et al. Visfatin: a protein secreted by visceral fat that mimics the effects of insulin. Science. 2005; 307: 426-30. doi: 10.1126/science.1097243, PMID: 15604363. 
8) Malam Z, Parodo J, Waheed F, Szaszi K, Kapus A, Marshall JC. Pre-B cell colony-enhancing factor (PBEF/Nampt/visfatin) primes neutrophilsfor augmented respiratory burst activity through partial assembly of theNADPH oxidase. J Immunol. 2011; 186: 6474-4. doi: 10.4049/jimmunol.1003706, PMID: 21518975.

9) Revollo JR, Grimm AA, Imai S. The regulation of nicotinamide adenine dinucleotide biosynthesis by Nampt/PBEF/visfatin in mammals. Curr Opin Gastroenterol. 2007; 23:164-70. doi: 10.1097/mog.0b013e32801b3c8f, PMID: 17268245.

10) Luk T, Malam $Z$, Marshal J. Pre-B cell colony enhancing factor (PBEF)/ visfatin: a novel mediator of innate immunity. J LeukocBiol. 2008; 83: 804-16. doi: 10.1189/jlb.0807581, PMID: 18252866.

11) Axelsson J, Witasp A, Carrero JJ, Qureshi AR, Suliman ME, Heimbürger O, et al. Circulating levels of visfatin/pre-B-cell colony-enhancing factor 1 in relation to genotype, GFR, body composition, and survival in patients with CKD. Am J Kidney Dis. 2007; 49: 237-44. doi: 10.1053/j.ajkd.2006.11.021, PMID: 17261426.

12) Yilmaz MI, Saglam M, Qureshi AR, Carrero JJ, Caglar K, Eyileten T. Endothelial dysfunction in type-2 diabetics with early diabetic nephropathy is associated with low circulating adiponectin. Nephrol Dial Transplant. 2008; 23: 1621-7. doi: 10.1093/ndt/gfm828, PMID: 18175782.

13) Malyszko J, Malyszko S, Mysliwiec M. Visfatin, a new adipocytokine, is predominantly related to inflammation/endothelial damage in kidney allograft recipients. Transplant Proc. 2009; 41: 150-3. doi: 10.1016/j.transproceed.2008.10.086, PMID: 19249500.

14) Yilmaz MI, Saglam M, Carrero JJ, Qureshi AR, Qureshi AR, Caglar K, et al. Serum visfatin concentration and endothelial dysfunction in chronic kidney disease. Nephrol Dial Transplant. 2008; 23: 959-65. doi: 10.1093/ndt/gfm727, PMID: 17984105.

15) Lotfy AW, Mohammed N, El-Tokhy HM, Attia A. Serum visfatin in chronic renal failure patients on maintenance hemodialysis: a correlation study. Egypt J Intern Med. 2013; 25: 202-8. doi: 10.4103/11107782.124982.

16) MalyszkoJ, Malyszko JS, Mysliwiec M. Visfatin and endothelial function in dialyzed patients. Nephrology (Carlton). 2010; 15(2): 190-6. doi: 10.1111/j.1440-1797.2009.01180.x, PMID: 20470278.

17) Go AS, Chertow GM, Fan D, McCulloch CE, Hsu CY. Chronic kidney disease and the risks of death, cardiovascular events, and hospitalization. N Engl J Med. 2004; 351(13): 1296-305. doi: 10.1056/NEJMoa041031, PMID: 15385656.

18) Keller C, Katz R, Sarnak MJ, Fried LF, Kestenbaum B, Cushman M, et al. Inflammatory biomarkers and decline in kidney function in the elderly: the Cardiovascular Health Study. Nephrol Dial Transplant. 2010; 25(1): 119-24. doi: 10.1093/ndt/gfp429, PMID: 19734138, PMCID: PMC2910326.

19) Iglesias P, Díez JJ. Adipose tissue in renal disease: clinical significance and prognostic implications. Nephrol Dial Transplant. 2010; 25: 2066-77. doi: 10.1093/ndt/gfq246, PMID: 20466661.

20) Bessa SS, Hamdy SM, El-Sheikh RG. Serum visfatin as a non-traditional biomarker of endothelial dysfunction in chronic kidney disease: an Egyptian study. Eur J Intern Med. 2010; 21: 530-5. doi: 10.1016/j.ejim.2010.09.011, PMID: 21111939.

21) Mu J, Feng B, Ye Z, Yuan F, Zeng W, Luo Z, et al. Visfatin is related to lipid dysregulation,endothelial dysfunction and atherosclerosis in patients with chronic kidney disease. J Nephrol. 2011; 24: 177-84. doi: 10.5301/JN.2010.3488, PMID: 20602330.

22) Carrero JJ, Witasp A, Stenvinkel P, Qureshi AR, Heimbürger O, Bárány P, et al. Visfatin is increased in chronic kidney disease patients withpoor appetite and correlates negatively with fasting serum amino acidsand triglyceride levels. Nephrol Dial Transplant. 2010; 25: 901-6. doi: 10.1093/ndt/gfp587, PMID: 19948877.

23) Mahmood N, Junejo AM, Jamal Q, Awan R. Association of visfatin withchronic kidney disease in a cohort of patients with and without diabetes. J Pak Med Assoc. 2010; 60: 922-6. PMID: 21375196.

24) Nüsken KD, Petrasch M, Rauh M, Stöhr W, Nüsken E, Schneider H, et al. Reduced plasma visfatin in end stage renal disease is associated with reduced body fat mass and elevatedserum insulin. Exp Clin Endocrinol Diabetes. 2007; 115: P01-052. doi: 10.1055/s-2007-972308.

25) Song H, Lee M, Kim B, Park Y, Ko G, and Kang Y. Visfatin: a new player in mesangial cell physiology and diabetic nephropathy. Am J Physiol Renal Physiol. 2008; 295: 1485-94. doi: 10.1152/ajprenal.90231.2008, PMID: 18768589.

26) Tang $X$, Chen $M$, Zhang W. Association between elevated visfatin and carotid atherosclerosis inpatients with chronic kidney disease. Zhong Nan Da Xue Xue Bao Yi Xue Ban. 2013; 38(6): 553-9. doi: 10.3969/j.issn.1672-7347.2013.06.002, PMID: 23828708. 
27) O'Keefe JH, Bell DS. Postprandial hyperglycemia/hyperlipidemia (postprandial dysmetabolism) is a cardiovascular riskfactor. Am J Cardiol. 2007; 100: 899-904. doi: 10.1016/j.amjcard.2007.03.107, PMID: 17719342.

28) Liu SW, Qiao SB, Yuan JS, Liu DQ. Association of plasma visfatinlevels with inflammation, atherosclerosis, and acute coronary syndromes in humans. ClinEndocrinol (Oxf). 2009; 71: 202-7. doi: 10.1111/j.1365-2265.2008.03453.x, PMID: 19178507.

29) Takebayashi K, Suetsugu M, Wakabayashi S, Aso Y, Inukai T, Association between plasma visfatin and vascular endothelial function in patients with type 2 diabetes mellitus. Metabolism. 2007; 56: 451-8. doi: 10.1016/j.metabol.2006.12.001, PMID: 17378999.

30) Teoh H, Lovren F, Verma S, Vascular dysfunction: a Janus face of visfatin in diabetes? Metabolism. 2007; 56: 459-61. doi: 10.1016/j.metabol.2006.12.002, PMID: 17379000.

31) Zhang T, Berrocal JG, Frizzell KM. Enzymes in the NAD+ salvage pathway regulate SIRT1 activity at target gene promoters. J Biol Chem. 2009; 284: 20408-17. doi: 10.1074/jbc.M109.016469, PMID: 19478080, PMCID: PMC2740465.

32) Van der Veer E, Nong Z, O’Neil C, Urquhart B, Freeman D, Pickering JG. Pre-B-cell colony-enhancing factor regulates NAD+- dependent protein deacetylase activity and promotes vascular smooth muscle cell maturation. Circ Res. 2005; 97: 25-34. doi: 10.1161/01.RES.0000173298.38808.27, PMID: 15947248.

33) Adya R, Tan BK, Punn A, Chen J, Randeva HS. Visfatin induces human endothelial VEGF and MMP-2/9 production via MAPK and PI3K/Aktsignalling pathways: novel insights into visfatininduced angiogenesis. Cardiovasc Res. 2008; 78: 356-65. doi: 10.1093/cvr/cvm111, PMID: 18093986. 